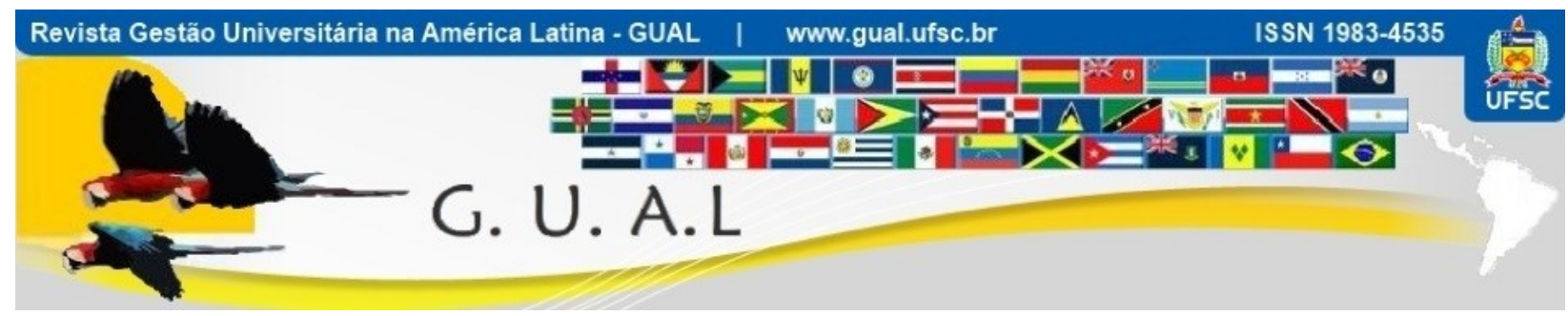

DOI: http://dx.doi.org/10.5007/1983-4535.2016v9n4p109

\title{
A UNIVERSIDADE EM EXPANSÃO: DA GESTÃO DO ENSINO À FORMAÇÃO DO CORPO TÉCNICO- ADMINISTRATIVO
}

\section{UNIVERSITY IN EXPANSION: FROM THE EDUCATION MANAGEMENT TO THE TECHNICAL AND ADMINISTRATIVE BODY TRAINING}

Cássio Cassel, Mestre Universidade do Vale do Rio dos Sinos - UNISINOS cassiocassell@hotmail.com

Taylyne Apollo, Tecnóloga Universidade do Vale do Rio dos Sinos - UNISINOS taylyne@outlook.com

Sônia Isabel Dondonis Daudt, Doutora

Universidade FEEVALE sddaudt@terra.com.br

Recebido em 04/dezembro/2015

Aprovado em 14/outubro/2016

Sistema de Avaliação: Double Blind Review

Esta obra está sob uma Licença Creative Commons Atribuição-Uso. 


\title{
A UNIVERSIDADEEM EXPANSÃO: DA GESTÃO DO ENSINO À FORMAÇÃO DO CORPO TÉCNICO- ADMINISTRATIVO \\ DOI: http://dx.doi.org/10.5007/1983-4535.2016v9n4p109
}

\section{RESUMO}

A partir do processo de expansão do ensino superior e do enfoque ao promissor mercado universitário instaurados no Brasil, este estudo analisou as tecnologias educacionais, enquanto ferramentas de apoio à gestão e ao desenvolvimento de equipes. Para isso, além de revisão bibliográfica em relação às políticas e tecnologias educacionais, este estudo de caso contou com a observação participante, a qual possibilitou o aprofundamento na realidade dos gestores responsáveis por equipes atuantes em unidades distantes da sede principal. No decorrer do estudo, percebeu-se que a instituição, que utiliza tecnologias educacionais avançadas e tem sido reconhecida pela excelência no ensino, demonstra enorme dificuldade para o desenvolvimento de suas equipes, o que evidenciou um desalinhamento, sobretudo da área de Recursos Humanos, em comparação às áreas de ensino. Frente a isso, o estudo reforça a necessidade de todas as áreas de uma instituição estarem alinhadas aos processos de expansão, assim como, aponta para a importância das tecnologias educacionais na formação dos funcionários e alinhamento das equipes.

Palavras chave: Ensino a distância. Democratização do ensino. Universidade. Tecnologias educacionais.

\begin{abstract}
From the process of expansion of higher education and focus on the promising university market estableshed in Brazil, this study analyzed the educational technologies as tools to support the management and development of teams. Therefore, in addition to literature revision related to educational policies and technologies, this case study included participant observation, which made it possible to deepen the reality of the managers responsible for staff that work in units that are distant from the headquarters. During the study, it was observed that the institution, which uses advanced educational technologies and has been recognized for excellence in teaching, demonstrates enormous difficulty in the development of their teams, which showed a misalignment, particularly in the area of Human Resources compared to the teaching areas. Faced with this, the study reinforces the need for all areas of an institution to be aligned with the expansion process, and points to the importance of educational technologies in the training of employees and alignment of teams.
\end{abstract}

Key words: E-learning. Democratization of education. University. Educational technologies. 


\section{A UNIVERSIDADEEM EXPANSÃO: DA GESTÃO DO ENSINO À FORMAÇÃO DO CORPO TÉCNICO-

\section{INTRODUÇÃO}

Frente à crise do capitalismo, algumas estratégias encaminhadas pelo próprio sistema têm sido observadas, como o neoliberalismo, a globalização financeira e produtiva e a Terceira Via, a fim de sustentar e reparar este regime econômico, o que tem redefinido as fronteiras entre o público e o privado e, consequentemente, interferido nas políticas e rumos da educação (Peroni, 2012). Como reflexo deste contexto, nos últimos anos, o Brasil viveu um período de intensa expansão do ensino superior, através da ampliação de benefícios e facilidades de acesso à população. Destarte, enquanto a educação superior assume um viés democrático, os incentivos dados à expansão universitária fazem com que o ensino superior passe a constituir um promissor mercado no país. Frente a este movimento, diferentes perfis de instituição de ensino, com diferentes objetivos para sua atuação, revelam-se integrantes deste cenário, expandindo sua atuação a partir das novas oportunidades.

Nesta circunstância, uma universidade do sul do país, presente no cenário acadêmico há mais de quarenta anos, posicionada sob os preceitos de excelência acadêmica e desenvolvimento humano, e visando ser uma universidade global de pesquisa, desenvolve e executa seu projeto de expansão. Em aproximadamente uma década, altera sua lógica de universidade, centralizada em um único campus, e passa a estar presente em mais de dez cidades, situadas em cinco estados brasileiros. Neste movimento, a necessidade de manter e desenvolver seus ideais de qualidade e excelência descortina novos desafios, como o acompanhamento do aprendizado dos alunos, sua formação humana e o alinhamento do corpo docente e administrativo aos objetivos e valores institucionais, que devem nortear sua atuação.

Diante dos obstáculos encontrados, e no intuito de ampliar o acesso à educação, tecnologias educacionais têm sido desenvolvidas, tornando-se essenciais para a implementação e o acompanhamento dos processos pedagógicos, possibilitando a execução das atividades acadêmicas, a interlocução entre os diferentes sujeitos que compõem a educação a distância, a avaliação do aprendizado e o acompanhamento do processo acadêmico dos alunos. Em contrapartida, neste universo, as instituições parecem estar focadas nos processos de ensino voltados aos alunos, não percebendo que estas tecnologias podem assumir, também, funções relacionadas ao desenvolvimento do quadro docente e da equipe técnico-administrativa. 


\section{A UNIVERSIDADEEM EXPANSÃO: DA GESTÃO DO ENSINO À FORMAÇÃO DO CORPO TÉCNICO- ADMINISTRATIVO \\ DOI: http://dx.doi.org/10.5007/1983-4535.2016v9n4p109}

Considerando o contexto exposto, este texto se concentrará na discussão entorno da democratização da educação, analisando o movimento de expansão da instituição de ensino mencionada e a forma como as tecnologias educacionais têm apoiado este processo. Em seguida, o estudo enfocará nos desafios relativos à formação do corpo técnico-administrativo atuante nas diferentes cidades em que a Universidade está presente. Assim, esta pesquisa buscou responder a seguinte questão: de que forma as tecnologias educacionais podem contribuir na formação do corpo técnico-administrativo de uma universidade em expansão? Para isso, utilizou-se a observação participante, que permitiu maior compreensão sobre a estrutura e as estratégias da instituição, assim como possibilitou a coleta da percepção dos agentes envolvidos na gestão e na formação de funcionários e professores pertencentes às unidades fora sede. A observação realizada, neste estudo, parte da interação entre os pesquisadores e os pesquisados, sendo que as informações coletadas buscaram a neutralidade em termos de análise, ao mesmo tempo em que, devido ao vínculo existente entre os investigadores e o caso de estudo, mostraram a relevância em coletar dados não utilizando apenas métodos formais de investigação.

\section{POLÍTICAS EDUCACIONAIS E A EXPANSÃO UNIVERSITÁRIA}

A compreensão do movimento de expansão do ensino superior e, consequentemente, da instituição analisada, depende também do entendimento do contexto econômico e político que tem oportunizado e incentivado a expansão da educação. Neste sentido, partindo do pressuposto de que as políticas educacionais não são determinadas por mudanças econômicas e sociais, mas são parte constitutiva delas, Peroni (2012) aponta para a redefinição que os movimentos capitalistas fazem das responsabilidades do Estado. Desta forma, discute a crise global, atualmente enfrentada pelo capitalismo, a qual entende-se que não se caracteriza pela geração de colapsos, mas por mudanças graduais na lógica do mercado e no escopo de atuação do Estado. Assim, apresenta, com o mesmo entendimento da teoria neoliberal, que a necessidade de atender as demandas da população por políticas sociais provocou a crise físcal do Estado e atrapalhou o livre andamento do mercado, a Terceira Via, a qual propõe uma alternativa ao neoliberalismo, a partir de um regime situado entre o estado mínimo e o estado como executor das políticas sociais universais. Este regime consistiria em uma parceria entre o terceiro setor e a reforma do Estado, que tem sua responsabilidade minimizada, ao mesmo tempo em que racionaliza os recursos públicos. 


\title{
A UNIVERSIDADEEM EXPANSÃO: DA GESTÃO DO ENSINO À FORMAÇÃO DO CORPO TÉCNICO- ADMINISTRATIVO \\ DOI: http://dx.doi.org/10.5007/1983-4535.2016v9n4p109
}

Em relação à redefinição do papel do Estado e aos processos de minimização dos direitos sociais, Peroni (2012, p. 6) afirma:

\begin{abstract}
As políticas educacionais materializaram esses processos de redefinição do papel do Estado, reorientando a relação entre público e privado. No entanto, é preciso destacar que essa relação é histórica e que diferentes grupos do setor privado influenciaram os governos na formulação de políticas educacionais. Neste sentido, a luta pela democratização da sociedade e da educação, em particular, estavam em um momento importante para a conquista de direitos, quando os setores privados se organizaram no sentido de garantir que sua proposta educacional fosse implementada.
\end{abstract}

Santos (2010) também disserta acerca da redução da responsabilidade do Estado, em relação ao seu compromisso com a universidade e a educação, o que se desenvolve a partir da descapitalização da universidade pública. $\mathrm{O}$ autor analisa que a redução da responsabilidade do Estado com a universidade fez com que ela precisasse desenvolver alternativas para se manter, e a opção desenvolvida e estimulada foi sua mercadorização. Tal fenômeno se deu em duas fases, a primeira entre as décadas de 1980 e 1990, quando se consolidou o mercado nacional universitário, e a segunda quando emergiu o mercado transnacional da educação superior e universitária que, no final da década de 1990, transmutou-se para o Banco Mundial e para a Organização Mundial do Comércio, numa possibilidade de solução global dos problemas de educação. Assim, a capacidade de produzir e difundir conhecimento e informação e de gerar novos produtos e serviços passou a ocupar lugar de destaque no cenário econômico, levando o lastro educacional a envolver também um importante valor financeiro.

Os encaminhamentos globais fizeram com que, no Brasil, ao longo do mandato do presidente Fernando Henrique Cardoso, fosse promovida uma importante reforma, a qual modernizou o modelo de políticas educacionais e descentralizou a gestão do ensino. As mudanças realizadas por este governo demonstram racionalidade, e, ainda, incremento nos instrumentos de avaliação em larga escala. Por sua vez, o governo Lula, cognominado dessa forma devido ao ex-presidente Luiz Inácio Lula da Silva, manteve, em seu primeiro mandato, a base educacional desenvolvida e implementada anteriormente. No entanto, a partir do seu segundo mandato, uma grande ruptura do modelo político existente foi acarretada, devolvendo ao Estado o protagonismo na educação, o qual se apropriou das diretrizes e passou a monitorar o desempenho educacional, que passa a ser balizado por indicadores, os quais, em grande parte, são extraídos dos instrumentos de avaliação em larga escala. Estes instrumentos de avaliação se desenvolveram ao ponto de se tornarem os grandes medidores de qualidade do ensino no país, o que passou a nortear a atuação de todas as instituições de 


\section{A UNIVERSIDADEEM EXPANSÃO: DA GESTÃO DO ENSINO À FORMAÇÃO DO CORPO TÉCNICO- ADMINISTRATIVO \\ DOI: http://dx.doi.org/10.5007/1983-4535.2016v9n4p109}

ensino. Oliveira (2009) evidencia que outro grande destaque deste Governo foi a forma como a mercadorização se desenvolveu e ao mesmo tempo foi neutralizada pela implementação de políticas e programas que visaram à ampliação do acesso ao ensino superior e à diminuição das diferenças sociais da população.

Diante do universo apresentado, percebe-se que o ensino se consolidou como uma valiosa mercadoria, e o mercado universitário, em expansão, fez com que diferentes instituições, com distintos motivadores e projetos político-pedagógicos, identifiquem as grandes oportunidades latentes no país. Assim, o processo de democratização da educação instaura um sinuoso ambiente competitivo, composto por instituições pertencentes ao primeiro, segundo e terceiro setor da economia, o que faz com que o Estado tenha que desenvolver estratégias, a fim de garantir seus próprios princípios e pressupostos pedagógicos. Frente a isso, os instrumentos de avaliação do Estado passaram a exercer papel fundamental para a avaliação da qualidade do ensino, a partir dos parâmetros estipulados, nas diferentes instituições, assim como, passaram a apoiar o reconhecimento das instituições comprometidas com a qualidade do ensino.

Como as instituições de ensino, comprometidas com a excelência e o desenvolvimento da sociedade, podem garantir sua expansão sem comprometer a qualidade de entrega? Das alternativas que têm se despontado neste contexto, as tecnologias educacionais se constituem como ferramentas importantes para o apoio dos processos de ensino e de aprendizagem. A partir de então, cabe a abordagem desta discussão.

\section{AS TECNOLOGIAS EDUCACIONAIS COMO PROPULSORAS DA EXPANSÃO}

Considerando o progressivo acesso do brasileiro à educação superior, que se intensificou na última década, as tecnologias educacionais se mostram como aliadas e propulsoras para a expansão universitária, principalmente através do ensino a distância. Embora esta modalidade de ensino tenha diversos benefícios, ao mesmo tempo, enfrenta dificuldades inerentes ao modelo de aprendizagem. Para os agentes do ensino a distância, o acompanhamento do aprendizado do aluno é mais intrincado, pois é uma tarefa árdua acompanhar seus rendimento e real participação. Além disso, dependendo do modelo adotado para a $\mathrm{EaD}$, há o risco da diminuição da cobrança e do desenvolvimento humanístico. Frente a tais aspectos, um conjunto de ferramentas se faz necessário para o atingimento de ações pedagógicas e do acompanhamento da trajetória dos alunos. 


\section{A UNIVERSIDADEEM EXPANSÃO: DA GESTÃO DO ENSINO À FORMAÇÃO DO CORPO TÉCNICO- ADMINISTRATIVO \\ DOI: http://dx.doi.org/10.5007/1983-4535.2016v9n4p109}

Rigo, Cazella e Cambruzzi (2014) apontam para a estratégia de mineração de dados como uma forma de se antever dificuldades e realizar ações pedagógicas relevantes. Através da identificação dos acessos aos ambientes de aprendizagem e do conhecimento prévio do perfil de atuação dos alunos em determinadas disciplinas, por exemplo, torna-se possível, inclusive, a prevenção da evasão escolar e o favorecimento da autonomia e flexibilidade discente. Nesse sentido, alguns recursos digitais se apresentam como elementos de apoio no ensino superior. Isto posto, entende-se que a mineração subsidia os tutores e professores para diferentes formas de acompanhamento de resultados.

Os ambientes virtuais de aprendizagem, por intermédio de ferramentas de relacionamento (como fóruns ${ }^{1}$, chats $^{2}$ e notícias na comunidade ${ }^{3}$ ), são exemplos de formas para se gerar alertas e interações com os alunos de maneira rápida e dinâmica. Desta forma, além de ajudarem na comunicação, os ambientes de aprendizagem também possibilitam a mineração de dados, propiciando a construção do perfil de cada membro da comunidade, assim como, o desenvolvimento de estratégias para qualificar os resultados institucionais, de acordo com os objetivos propostos. As tecnologias educacionais e a mineração de informações possibilitam, por exemplo, de acordo com Rigo, Cazella e Cambruzzi (2014), a geração de alertas a serem utilizados pelos professores e tutores, o que facilita a implementação de ações preventivas e tira o docente de uma posição reativa, tornando-o proativo a tendências e comportamentos. Afinal, ao acompanhar as interações e movimentações feitas pelos alunos, torna-se mais assertivo depreender as ações adequadas à qualidade do aprendizado.

\section{UMA UNIVERSIDADE EM EXPANSÃO}

Antes de abordar a Universidade examinada, cabe apresentar a metodologia utilizada para a investigação. Correia (2009) explica a observação participante como uma metodologia

\footnotetext{
${ }^{1}$ É uma ferramenta que oportuniza discussões de caráter colaborativo (DE OLIVEIRA, 2011).

${ }^{2}$ Conforme Houaiss (2001), "é uma forma de comunicação a distância, utilizando computadores ligados à internet, na qual o que se digita no teclado de um deles aparece em tempo real no vídeo de todos os participantes do bate-papo".

${ }^{3}$ Nestes casos, os professores, quando querem informar algo à turma, utilizam espaços digitais exclusivos para divulgações desta espécie. Os alunos, cadastrados em um sistema de recebimento de alertas através da interligação com seus e-mails pessoais, recebem em seus próprios endereços eletrônicos uma cópia da notificação feita. Da mesma maneira, quando um aluno faz uma postagem em um fórum, os colegas e o professor também recebem cópias do conteúdo, gerando mútua cognição. Para Cerveira (2009, p. 13), "alertas são gerados a partir de agrupamentos de alunos com características similares, para que o professor possa estabelecer comunicação personalizada e contextualizada com esses sujeitos".
} 


\section{A UNIVERSIDADEEM EXPANSÃO: DA GESTÃO DO ENSINO À FORMAÇÃO DO CORPO TÉCNICO- ADMINISTRATIVO \\ DOI: http://dx.doi.org/10.5007/1983-4535.2016v9n4p109}

empregada quando o investigador atuante é o próprio instrumento de pesquisa. Ou seja, é um caso em que quem investiga está envolvido no caso pesquisado. Para que seja utilizada, sugere a reunião de critérios, como sujeitar a análise dos resultados à validação e à verificação. Outra das ponderações necessárias é a eliminação da subjetividade e da imparcialidade, de forma que os fatos possam ser compreendidos em seu contexto. No entanto, embora exista a precaução em não se sugestionar quanto à neutralidade, também despontam uma série de prerrogativas no uso da técnica. Para Amendoeira (1999), o investigador terá uma clara vantagem, dada a possibilidade de coleta de dados em contextos naturais e acesso à linguagem usada no dia-a-dia (já que na observação participante pode-se conhecer melhor a linguagem dos intervenientes). Os autores do presente estudo atuam na universidade investigada e possuem proximidade ao objeto de estudo. Desta forma, considerando seu pertencimento à realidade investigada, o método utilizado foi, justamente, a observação participante, a qual exigiu a busca por imparcialidade, ao mesmo tempo que, conforme o referencial apresentado, facilitou o aprofundamento na realidade da instituição, favorecendo a obtenção e a compreensão das informações.

A universidade analisada para o desenvolvimento deste artigo desenvolveu sua estratégia de expansão tendo como pressupostos os mesmos valores e diretrizes que a regem desde sua criação. A Instituição tem como objetivo permanente distinguir-se pelo desenvolvimento de um ambiente de excelência acadêmica e assegurar um ensino de qualidade, com sólidas bases científicas, de forma transdisciplinar e com visão atualizada de mundo, domínio e aplicação de tecnologias educacionais, formas participativas e práticas inovadoras. No que tange a seus recursos humanos, ela demonstra o desejo de roborar o preparo e a formação de pessoas solidárias, qualificadas, comprometidas, dedicadas e dispostas ao aprendizado contínuo. Seu intuito é assegurar um modelo organizacional flexível e eficiente, bem como práticas de gestão eficazes e adequadas as suas necessidades e às exigências do mercado e da comunidade.

Um dos princípios de gestão da instituição analisada é a integração entre as diferentes funções administrativas e acadêmicas. Neste sentido, a instituição busca a qualidade em seus processos e atividades, por meio da identificação, da mobilização e do desenvolvimento de competências pessoais e gerenciais. Sua orientação é para a inovação, as mudanças e os resultados. Seu trabalho com ensino e pesquisa é reconhecido por avaliações de seus cursos de graduação e de seus programas de pós-graduação. Tal reconhecimento destaca-se pelos 


\section{A UNIVERSIDADEEM EXPANSÃO: DA GESTÃO DO ENSINO À FORMAÇÃO DO CORPO TÉCNICO- ADMINISTRATIVO \\ DOI: http://dx.doi.org/10.5007/1983-4535.2016v9n4p109}

resultados obtidos em avaliações realizadas pelo $\mathrm{INEP}^{4}$, pelo $\mathrm{MEC}^{5}$ e pela $\mathrm{CAPES}^{6}$, além de notas no Enade ${ }^{7}$. O conceito avaliativo utilizado varia de 1 a 5 e a Universidade investigada, de acordo com a página oficial do MEC, é uma associação privada, qualificada como comunitária, com Conceito Institucional (CI) 4 e Índice Geral de Cursos (IGC) $4^{8}$, o que revela sua tradição e reforça seu compromisso com o desenvolvimento social e com a qualidade do ensino.

Como a instituição busca pela integração e pela excelência na formação de seu corpo discente e de seu corpo técnico-administrativo, é válido aprontar que a mesma aparenta preocupar-se com o aperfeiçoando de ambos os públicos (interno e externo), pois mostra que há preocupação na utilização de tempo e recursos quando a pauta é a formação de seu corpo docente e técnico-administrativo. Neste movimento, percebe-se que a educação a distância passou a ser um dos focos de investimento da universidade, uma vez que sua gestão é estratégica para a instituição, devido ao novo panorama da educação. De acordo com Bernardi, Daudt e Behar (2013, p.1), a "ampliação da oferta de cursos a distância tem obrigado às instituições de ensino superior (IES) a conviver com novas formas de ver e organizar a educação universitária", o que aponta para a necessidade de desenvolvimento de novas estratégias de gestão, capazes de garantir o sucesso desta modalidade de ensino. Visto isso, infere-se que o uso das tecnologias educacionais pode, ainda, lapidar os programas de capacitação do corpo técnico-administrativo, o que tende a contribuir para a fomentação da gestão do conhecimento.

\footnotetext{
${ }^{4}$ O Instituto Nacional de Estudos e Pesquisas Educacionais Anísio Teixeira é uma autarquia federal vinculada ao Ministério da Educação (MEC), cuja missão é promover estudos, pesquisas e avaliações sobre o Sistema Educacional Brasileiro com o objetivo de subsidiar a formulação e implementação de políticas públicas para a área educacional a partir de parâmetros de qualidade, bem como produzir informações claras e confiáveis aos gestores, pesquisadores, educadores e público em geral (BRASIL, 2011).
}

${ }^{5}$ O Ministério da Educação estabelece como área de competência a educação em geral, compreendendo ensino fundamental, ensino médio, ensino superior, ensino de jovens e adultos, educação profissional, educação especial e educação a distância, exceto ensino militar (BRASIL, 2015).

${ }^{6}$ A Coordenação de Aperfeiçoamento de Pessoal de Nível Superior é o órgão do Ministério da Educação responsável pela avaliação continuada das pós-graduações stricto sensu no país (BRASIL, 2014).

${ }^{7}$ O Exame Nacional de Desempenho de Estudantes tem como principal objetivo avaliar o desempenho dos alunos dos cursos de graduação em relação às competências desenvolvidas ao longo dos cursos em que estão matriculados (BRASIL, 2015).

${ }^{8}$ O CPC é obtido a partir do desempenho dos estudantes no Enade e considera, também, outros insumos, tais como: corpo docente, infraestrutura e projeto pedagógico do curso (ENADE, 2011). 


\section{A UNIVERSIDADEEM EXPANSÃO: DA GESTÃO DO ENSINO À FORMAÇÃO DO CORPO TÉCNICO- ADMINISTRATIVO \\ DOI: http://dx.doi.org/10.5007/1983-4535.2016v9n4p109}

$\mathrm{Na}$ instituição analisada, a gestão da Educação a Distância está centrada em um tripé que articula os processos administrativo, pedagógico e tecnológico. Bernardi, Daudt e Behar (2013) abordam os conceitos de administração sob a perspectiva educacional, compreendendo que é possível refletir sobre a gestão educacional a partir de princípios administrativos, vendo neles importantes mecanismos de acompanhamento de resultados. Bernardi e Moresco (2011) discutem o modelo pedagógico, constituído por uma arquitetura pedagógica, o qual é conceituado como um conjunto sistêmico de premissas teóricas que representam, explicam e orientam a forma como o currículo é abordado para a concretização das práticas pedagógicas. Em ambas discussões, percebe-se a relação necessária entre as concepções que pautam as ações administrativas, pedagógicas e tecnológicas, necessárias à execução de um bom processo de aprendizagem e à obtenção de resultados esperados.

Os sistemas computacionais mostram-se coligados à aprendizagem e ao combate à evasão. Através de um Ambiente Virtual, especificamente, o ensino torna-se menos laborioso e meandroso ao aluno e/ou ao funcionário. Amparadas por tecnologias que permitem a interação dos estudantes entre eles mesmos e com os demais agentes envolvidos no modelo de aprendizagem, como coordenadores, professores e tutores, as ferramentas administrativas atuam como valorosos patamares à educação de qualidade. Outrossim, essas ferramentas permitem aos estudantes o acompanhamento de atividades, através do monitoramento de acessos e, até mesmo, do controle de suas tendências à evasão, por intermédio de um complexo modelo de mineração de dados. Rigo, Cazella e Cambruzzi (2014) reforçam que quando os resultados são adequadamente gerados, entra em questão a utilização destas informações, que, idealmente, devem estar associadas com ações institucionais. Nesta perspectiva, torna-se possível o vislumbre da relação entre os elementos componentes do tripé da gestão educacional.

A abordagem realizada explicita a concretude dos processos acadêmicos desenvolvidos pela instituição estudada, assim como, a relevância atribuída ao uso das ferramentas tecnológicas, frente à consolidação da qualidade do ensino de graduação a distância ofertado. Em 2014, os resultados das avaliações dos cursos de graduação a distância, promovidas pelo Ministério da Educação (MEC), reforçam este argumento, visto que os cursos avaliados ficaram com pontuação 4 ou 5, em uma escala de 1 a 5. Apesar disso, um ensino de qualidade requer uma estrutura administrativa também qualificada, a fim de garantir o devido apoio às atividades acadêmicas. Neste sentido, considerando os objetivos de análise 


\section{A UNIVERSIDADEEM EXPANSÃO: DA GESTÃO DO ENSINO À FORMAÇÃO DO CORPO TÉCNICO-

desta pesquisa, direciona-se o foco à estrutura da Universidade, especialmente às áreas de apoio administrativo.

\subsection{A RELEVÂNCIA DA BASE ADMINISTRATIVA E DAS EQUIPES DE ATENDIMENTO NA BUSCA PELA EXCELÊNCIA}

A estrutura organizacional é uma maneira de entrever as atividades institucionais, porquanto além de abranger a divisão do trabalho, costuma mostrar a hierarquia e as estratégias de uma instituição. De acordo com Valentim (2005, p.1), “a estrutura organizacional é muito importante para a efetividade da gestão da informação e do conhecimento, pois é a partir dela, da estrutura, que os fluxos informacionais se desenvolvem". A Universidade em questão, por sua vez, possui uma estrutura organizacional matricial, descentralizada e, dessa forma, busca uma comunicação corporativa eficiente entre seus setores. No topo de sua estrutura ${ }^{9}$, a universidade analisada possui um conselho universitário, um colegiado e câmeras de graduação, pós-graduação, pesquisa e extensão. A reitoria, composta pelo reitor, o vice-reitor e os pró-reitores acadêmico e de administração, tem o assessoramento de uma auditoria interna, do gabinete da reitoria, da procuradoria geral, da assessoria de comunicação e marketing e da controladoria acadêmica de avaliação institucional. Subsequentemente, a universidade detém unidades acadêmicas (Graduação, Pesquisa e Pós-graduação e Educação Continuada) e unidades de apoio. Estas têm, como órgãos suplementares, a biblioteca universitária, uma editora própria e uma gerência de ação social. A quota de apoio contempla as áreas de Relações Internacionais, de Gestão Financeira e de Pessoas, infraestrutura e serviços acadêmicos, onde se concentram as equipes de atendimento e de apoio, unidade na qual o presente artigo pormenorizou a análise.

A Unidade de Serviços Acadêmicos, responsável pelo apoio a todos os processos de cunho acadêmico, conta com: uma gerência que atende às necessidades dos alunos (assistência acadêmica, orientação vocacional e profissional, entre outros); uma gerência de Atendimento (responsável pelo contato direto com o corpo discente, para atendimento de processos de matrícula e gerenciamento do relacionamento); uma gerência de Registros Acadêmicos (incumbida do acompanhamento dos registros dos alunos, desde sua entrada e durante toda a vida acadêmica); uma gerência de Serviços de Apoio Compartilhados (composta por secretarias e postos de atendimento distribuídos pelos Campi); uma

\footnotetext{
${ }^{9}$ Os dados foram retirados dos regimentos e ofícios da Universidade, que, por motivo de sigilo não foram relacionados nas relações bibliográficas do presente artigo.
} 
Coordenação de Eventos (diligência de eventos institucionais, promocionais e acadêmicos); e uma Coordenação de Salas de Informática (responsável por todos os espaços de informática pelo maneio dos softwares e hardwares, utilizados por todos os níveis de ensino). A Unidade de Serviços Acadêmicos tem formalizadas as suas diretrizes e objetivos e apresenta, como missão, oferecimento ao público de serviços reconhecidos por sua excelência e inovação, e a promoção da formação contínua e a atuação solidária e inclusiva para o desenvolvimento da pessoa humana e da sociedade, o que demonstra sua intenção de fornecer à comunidade serviços acadêmicos de excelência. Diante dos objetivos de sua existência, a unidade demonstra articulação e alinhamento com a missão e os objetivos institucionais.

Para que tais objetivos sejam alcançados, é pertinente observar as práticas de formação e desenvolvimento das equipes vinculadas a esta unidade, o que terá impacto direto na qualidade das entregas institucionais. Faz-se importante destacar que as equipes vinculadas a esta estrutura apoiam as atividades acadêmicas presenciais, mas também as atividades dos cursos ofertados na modalidade a distância. Desta forma, indaga-se, de que forma a instituição tem utilizado sua expertise em gestão do ensino a distância para a gestão das equipes de apoio?

\section{CASA DE FERREIRO, ESPETO DE PAU? A FORMAÇÃO DO CORPO TECNICO- ADMINISTRATIVO E DO MODELO PEDAGÓGICO DA INSTITUIÇÃO ${ }^{10}$}

Conforme visto, as tecnologias educacionais têm assumido um importante papel no processo de expansão da Universidade. A instituição analisada, em curto espaço de tempo, passou a estar presente, fisicamente, em cada um de seus polos de educação a distância, consolidados em diversas cidades, e ainda em um novo Campus instalado em uma capital brasileira. Esta ampliação de atuação faz com que sua performance dependa, também, de um corpo técnico-administrativo alinhado aos valores e pressupostos institucionais e desenvolvido para desempenhar tecnicamente sua função. Mas como garantir o alinhamento entre equipes distantes geograficamente?

Pereira (2009, p.3), em relação às necessidades para o desenvolvimento da Universidade, afirma:

\footnotetext{
${ }^{10}$ É possível observar casos em que alguém, apesar de possuir experiência teórica e prática em relação a algo, não consegue replicar o conhecimento em todas as esferas a que se expõe. Como visto em Machado e Silveira (2014), o ditado popular "casa de ferreiro, espeto de pau" tem o equivalente em inglês "the shoemaker's son always goes barefoot" (em tradução livre: o filho do sapateiro sempre anda descalço). Tal ditado aplica-se bem à essência do que ocorre, não raramente, em diversas instituições de ensino e organizações de forma geral.
} 


\title{
A UNIVERSIDADEEM EXPANSÃO: DA GESTÃO DO ENSINO À FORMAÇÃO DO CORPO TÉCNICO- \\ DOI: http://dx.doi.org/10.5007/1983-4535.2016v9n4p109
}

\begin{abstract}
São necessárias duas condições: a interna, do esforço do indivíduo, e a externa, vinda da estrutura e do financiamento. Caracterizando o que a universidade deveria promover, Humboldt é explícito ao afirmar que sua finalidade é o enriquecimento moral da Nação e do indivíduo. (PEREIRA, 2009).
\end{abstract}

Ao analisar este posicionamento, o qual possui direta concordância com o que se sabe sobre a necessidade de aprimoramento contínuo, cabe evidenciar a importância de se atentar não somente às condições para o melhor desenvolvimento acadêmico, mas também às condições da formação do corpo técnico-administrativo, que é quem sustenta a base operacional da organização. Neste sentido, deve ser considerado o desenvolvimento de competências relativas à prática de atendimento, desde os elementos técnicos até os aspectos comportamentais. Formar alguém se atentando para suas idiossincrasias é pensar no papel fundamental da integridade em qualquer âmbito. $\mathrm{O}$ conhecimento e as experiências vividas pelos membros de uma organização são os fatores contribuintes para o direcionamento dos esforços de disseminação de informação e, consequentemente, para o atingimento dos resultados esperados pela instituição.

Com este entendimento, e olhando para a forma como a Universidade tem se posicionado na educação a distância, a resposta mais lógica para a indagação sobre o desenvolvimento de equipes que atuam em estruturas distantes geograficamente poderia ser a adoção do modelo utilizado para a graduação a distância, como um caminho oportuno para a formação das equipes de trabalho. No entanto, através da observação participante, é possível perceber que, atualmente, na Universidade investigada, apesar da existência de um tripé bem consolidado para a execução do ensino a distância, a formação técnico-administrativa se constitui em um sistema distinto, não sistematizado e pouco apoiado por tecnologia.

Neste momento, cabe especificar a forma como a observação participante foi realizada. A Unidade de Serviços, apresentada anteriormente é responsável pela operacionalização e apoio de todas as atividades acadêmicas. Seu corpo técnicoadministrativo, muitas vezes, atua como principal interlocutor de alunos, professores, tutores e demais atores da comunidade universitária, o que evidencia a importância de seu preparo técnico e comportamental, principalmente no que tange a sua atuação em termos de atendimento, a fim de garantir o alcance dos objetivos institucionais. Para isso, comporta, aproximadamente, trinta por cento do quadro funcional da instituição, o que significa mais de trezentas e cinquenta pessoas, distribuídas em quatro gerências e duas coordenações que, embora separadas em termos terminológicos, de forma simbiótica, mantêm como principal 


\section{A UNIVERSIDADEEM EXPANSÃO: DA GESTÃO DO ENSINO À FORMAÇÃO DO CORPO TÉCNICO- ADMINISTRATIVO \\ DOI: http://dx.doi.org/10.5007/1983-4535.2016v9n4p109}

objetivo serem partícipes de uma unidade que se movimenta em prol da excelência. Portanto, a fim de alinhar a formação de suas equipes, os gestores destas áreas, em conjunto com a área de Recursos Humanos (RH), instituíram um grupo articulador (com representantes), responsável pela organização das necessidades, planejamento das capacitações anuais e acompanhamento dos resultados. Os autores deste texto tiveram a oportunidade de compor o grupo, o qual, em diferentes momentos, reuniu-se com os gestores da Unidade de Serviços e da área de RH, recebendo demandas, avaliações críticas, frustrações e reconhecimentos. Desta atuação, foi possível a coleta privilegiada de dados capazes de subsidiar este estudo, assim, a percepção do cenário apresentado se constituiu a partir do conhecimento do processo de contratação e de observações de gestores e afins, coletadas em reuniões em prol da definição de diretrizes e passos a serem seguidos e registrados em um diário de campo.

O grupo teve início há quatro anos e, de acordo com os registros das discussões iniciais, quando os gestores e seus representantes identificavam as premissas e necessidades para este trabalho, as principais demandas eram: falta de alinhamento das capacitações para as diferentes áreas que, em tese, deveriam ter demandas de desenvolvimento de equipes, comuns; ineficiência nas ofertas, considerando que as capacitações eram ofertadas de forma aleatória, sem considerar o calendário de atividades das áreas, nem os turnos críticos; falta de alcance das equipes atuantes fora da sede; baixa quantidade de funcionários efetivamente capacitados para sua atuação. Nota-se que existia uma inconformidade dos gestores com o modelo até então apresentado pela área de Gestão de Pessoas, pois a única forma de capacitar um funcionário, até então, dava-se através da modalidade presencial, que era bastante restrita, já que as ofertas centralizavam-se no campus principal. Desta forma, para que um funcionário de fora desta sede pudesse participar, deveria se deslocar e, muitas vezes, pernoitar na cidade do campus, o que parecia erguer grandes barreiras para o desenvolvimento do quadro funcional.

Para ilustrar a percepção dos gestores, faz-se pertinente a exposição de suas falas, ainda nas primeiras discussões do grupo. Assim, parte-se para a fala do gestor 1:

É muito difícil desenvolver funcionários, dependendo de um programa de capacitações, unicamente, presencial. Minha equipe, para participar de capacitações, precisa viajar vários quilômetros e perder horas em deslocamento o que, muitas vezes, inviabiliza as participações. Sem falar quando precisam dormir fora de casa. 


\section{A UNIVERSIDADEEM EXPANSÃO: DA GESTÃO DO ENSINO À FORMAÇÃO DO CORPO TÉCNICO- ADMINISTRATIVO \\ DOI: http://dx.doi.org/10.5007/1983-4535.2016v9n4p109}

Por sua vez, outro gestor, chamado aqui de gestor 2 , também faz referência às dificuldades para as capacitações, evidenciando questões básicas que devem subsidiar a gestão:

Pra mim, é muito difícil entender quais capacitações atendem às necessidades da minha equipe. Não consigo entender a que eixo do plano de carreira elas estão enquadras, nem se estão desenvolvendo os funcionários de forma básica, intermediária ou avançada. Acabo os inscrevendo por intuição e torço pra que tenha feito as melhores escolhas.

O gestor, nesta fala, faz referência ao plano de carreira da instituição e à ferramenta de avaliação do desenvolvimento individual de cada funcionário. Neste sentido, cabe ressaltar que a Universidade investigada possibilita a progressão funcional de duas formas, através de promoção vertical ou horizontal, na qual é exigido o desenvolvimento de competências compatíveis com os estágios pretendidos. Assim, os funcionários pertencem a eixos, divididos de acordo com a complexidade de sua função. Cada eixo possui um conjunto de atribuições e conhecimentos que precisam ser superados, para que os funcionários possam galgar os estágios de carreira superiores, propostos pela instituição. Apesar de um modelo de carreira bastante estruturado, a falta de um plano integrado de desenvolvimento e de avaliação do conhecimento obtido apresenta-se como um abismo à execução do plano de carreira. É o que se percebe na fala do gestor 3 :

\footnotetext{
Além das pessoas terem que se deslocar para serem capacitadas, o monitoramento das presenças é falho e não há avaliação. Hoje, eu submeto um funcionário pra uma capacitação, dedicando tempo e expectativa para sua formação, mas não tenho a menor ideia dos resultados reais destas capacitações. Tenho informações apenas a partir dos funcionários, quando os questiono sobre sua participação. Em contrapartida, anualmente preciso avaliar os funcionários, através do instrumento institucional de gestão por competências, a partir de conhecimentos que, teoricamente, ele deveria ter desenvolvido nas capacitações, no entanto, na prática, não tenho nenhum subsídio concreto para isso.
}

Os posicionamentos dos gestores demonstram indícios da preocupante situação que o processo de formação do corpo técnico-administrativo estava submetido no início do trabalho do grupo articulador. Desde então, no decorrer de quatro anos, uma série de medidas foram adotadas. Em uma reunião recente, de apresentação de resultados e ponderação de desafios ainda latentes, foram apresentados os seguintes ganhos: alinhamento do perfil de funcionários e conhecimentos para cada eixo de carreira; estruturação do planejamento semestral do calendário de capacitações, construído através dos processos críticos de cada área; definição das capacitações essenciais para cada eixo de carreira, construindo um alinhamento das demandas, o que possibilitou maior eficiência no uso das vagas e no atingimento dos 


\section{A UNIVERSIDADEEM EXPANSÃO: DA GESTÃO DO ENSINO À FORMAÇÃO DO CORPO TÉCNICO-

objetivos das áreas; monitoramento das presenças das equipes nas capacitações; avaliações periódicas das capacitações e ações efetivas para casos em que se percebe desalinhamento dos objetivos em relação à proposta implementada; tentativa de desenvolvimento de um modelo a distância de capacitação.

Embora os ganhos tenham sido notáveis, o que se evidencia através da percepção de todos que atuam no grupo articulador, alguns desafios permanecem e se acentuam. É o caso da ineficiência no desenvolvimento dos funcionários atuantes fora da sede, o que permanece na fala do gestor 1 , que diz que "simplesmente a gente não avança, não consigo capacitar quem está fora do campus. É inviável fazer com que eles tenham que vir pra Universidade. As capacitações a distância não estão funcionando". O gestor 3 também reforça essa ideia, ao dizer que "as ferramentas são muito ruins e o conteúdo das capacitações a distância, da forma como tem sido exposto, tem desestimulado a participação dos funcionários que, a cada frustração, alimentam um preconceito maior com o modelo a distância”. Assim, buscou-se o entendimento de como o modelo a distância, para a implementação de capacitações, foi conduzido.

Diante das demandas iniciais, entregues ao grupo articulador, uma das primeiras medidas foi o desenvolvimento de capacitações corporativas na modalidade a distância. No entanto, ao invés de um alinhamento com o modelo já usado nas áreas acadêmicas, o RH, talvez por visar economia ou por desconhecimento do modelo já utilizado pela instituição (essa justificativa não está evidente), buscou por meios próprios a implementação do modelo. Desta forma, suas primeiras investidas foram extremamente mal sucedidas, sendo que a única ferramenta tecnológica utilizada foi a webconferência e o e-mail, por onde materiais de apoio foram enviados. Essa investida foi desestimulante para os participantes e seus gestores.

É importante destacar que, em suas participações no grupo, os representantes do RH reconhecem a necessidade da modalidade a distância e de ferramentas mais eficazes. Assim, motivados por discussões que apontam para a realidade do ensino a distância na instituição, o RH busca alternativas, mas acaba retornando com capacitações prontas, construídas para a Graduação, e usando apenas uma parte das ferramentas que a instituição possui. Desta forma, apesar de mais organizado, o modelo permanece incompatível com o que se almeja, já que desconsidera as reais necessidades destas equipes e não permite o acompanhamento individual dos participantes, como o monitoramento dos acessos, suas tendências de comportamento e avaliação do conhecimento obtido. De acordo com Schiavon (2008, p.5): 
Listas eletrônicas, fóruns de discussão, comunidades e dispositivos de pesquisa na rede configuram-se caminhos - muitas vezes mais atrativos e eficazes que as aulas para a troca de informação e produção de conhecimento. Aqueles que ainda estão se adaptando às novas tecnologias ou as introduzindo em suas comunidades sabem as dificuldades desse processo, pois exige uma reorganização física dos recursos materiais de modo a facilitar a instalação de novos aparelhos e estabelecer conexões entre professores, alunos e sociedade. Também haverá necessidade de pessoal e de infraestrutura competente para apoio e manutenção. Todos esses esforços, no entanto, valerão a pena. Ao acessar a rede e pesquisar, o aluno poderá experimentar uma percepção diferente das relações com os objetos, o tempo e o espaço.

\section{CONSIDERAÇÕES FINAIS}

A crise capitalista e as demandas da sociedade têm incentivado o desenvolvimento de estratégias que visam recuperar o capital e garantir o atendimento das necessidades sociais. No Brasil, a expansão do ensino superior tem sido acelerada através da esfera privada e, assim, instaurou-se uma acirrada arena de competição entre distintas instituições de ensino. Neste contexto, a educação a distância passa a ser um dos principais caminhos para a ampliação do ensino superior e tem impulsionado as instituições a desenvolverem novas metodologias de ensino e a buscarem novas ferramentas educacionais, o que tem possibilitado a ampliação de seus polos e sedes.

Diante do cenário exposto, as tecnologias educacionais mostram-se aliadas das instituições engajadas em oferecer educação com qualidade e apoiar o Estado no desenvolvimento da sociedade. Através de tais tecnologias, os professores expõem o conteúdo das atividades acadêmicas, além se as desenvolverem, estimulam a troca de conhecimento e experiências, acompanham os resultados individuais dos alunos e os orientam pedagogicamente. Através da mineração e do tratamento de dados, os professores e as instituições podem identificar necessidades de aproximação de alunos e de disciplinas, possibilidades de qualificação dos métodos de ensino e, até mesmo, acompanhar as tendências de evasão dos alunos. Com isso, as instituições ampliam a possibilidade de sucesso na relação do professor com o aluno e, ainda, conseguem acompanhar as tendências individuais e das disciplinas, a fim de tomar medidas de recuperação de conteúdo e desempenho.

Ao mesmo tempo em que as instituições de ensino superior buscam instrumentar o professor e desenvolver metodologias de ensino efetivas, a expansão universitária e a consolidação de polos distantes da sede principal também requerem atenção para a base operacional que apoia o ensino e a expansão. Assim, faz-se necessário enfocar nas equipes administrativas que apoiam os processos e garantem o atendimento dos alunos e professores. 
O estudo realizado apontou para uma instituição em pleno processo de expansão, a qual, primando por excelência, tem investido em tecnologias educacionais e garantindo bons resultados acadêmicos. Por outro lado, expõe as dificuldades de gerir e desenvolver as equipes de apoio que atuam em diferentes espaços e precisam garantir alinhamento processual e com os valores institucionais. Percebe-se que o conjunto de tecnologias em que a instituição tem investido para o ensino a distância não tem alcançado a área de $\mathrm{RH}$, mostrando não acompanhar o ritmo da expansão promovida pela instituição, o que lhe torna ineficiente e ineficaz.

Assim, entende-se que o processo de expansão deve contemplar todas as áreas da instituição e, portanto, estimular não apenas os setores focados no ensino, mas toda a organização, de forma a alinhar sua condução em prol do alcance aos alunos, professores e funcionários atuantes nas pontas de ensino. Com isso, indica-se a realização de novos estudos que enfoquem no uso de tecnologias educacionais para o desenvolvimento de equipes e, até mesmo, exponham resultados obtidos por organizações que alinharam esta prática.

\section{REFERÊNCIAS}

BEM, Roberta M. A gestão do conhecimento dentro das organizações: a participação do bibliotecário. Florianópolis: Revista ACB. 2006.

BERNARDI, Maira; DAUDT, Sônia I. D.; BEHAR, Patrícia A. Domínio da Gestão em educação a distancia: foco na coordenação de curso. São Paulo: Associação Brasileira de Educação a Distância. 2013.

BERNARDI, Maira; MORESCO, Sílvia. Competências docentes para a prática pedagógica na educação a distância: uma análise a partir do modelo pedagógico. Porto Alegre: UFRGS. 2011.

BRASIL. Ministério da Educação. Fundação Capes. Brasília, 2014. Disponível em: $<$ http://www.capes.gov.br/>. Acesso em: 08 set. 2015.

BRASIL. Instituto Nacional de Estudos e Pesquisas Educacionais Anísio Teixeira. Brasília, 2011. Disponível em: < http://portal.inep.gov.br/> Acesso em: 06 set. 2011.

BRASIL. Ministério da Educação. Instituto Nacional de Estudos e Pesquisas Educacionais Anísio Teixeira. Brasília, 2011. Disponível em: $<$ http://portal.inep.gov.br/web/guest/enade $>$. Acesso em: 07 set. 2015.

BRASIL. Ministério da Educação. Ministério da Educação. Brasília, 2015. Disponível em: < http://portal.mec.gov.br/ Acesso em: 07 set. 2015. 
CORREIA, Maria da C. B. A observação participante enquanto técnica de investigação. São Paulo: Scielo. 2009.

DE OLIVEIRA, Gerson P. O fórum em um ambiente virtual de aprendizado colaborativo. São Paulo: Associação Brasileira de Educação a Distância. 2011.

FILHO, Joaquim N. F. Educação corporativa em EaD: Benefícios da modalidade elearning. São Paulo: Associação Brasileira de Educação a Distância. 2011.

HOUAISS, Antonio. Dicionário Eletrônico Houaiss da Língua Portuguesa. Rio de Janeiro: EDITORA OBJETIVA, 2001.

KAMPFF, Adriana J. C. Mineração de dados educacionais para geração de alertas em ambientes virtuais de aprendizagem como apoio à prática docente. Porto Alegre: UFRGS. 2009.

MACHADO, Carla J.; SILVEIRA, Andréa M. Casa de ferreiro, espeto de pau: o tabagismo entre profissionais de saúde. São Paulo: Scielo. 2014.

MARQUES, José R. Plano de desenvolvimento Individual - O que é o PDI? Disponível em: $<$ http://www.ibccoaching.com.br/tudo-sobre-coaching/coaching-carreira/plano-dedesenvolvimento-individual/>. Acesso em: 15 agosto 2015.

NETTO, Gabriela B; DAMINI, Nedir R. O atendimento ao cliente como estratégia de sucesso. Brasília: UniCEUB. 2011.

OLIVEIRA, Dalila A. As políticas educacionais no governo Lula: rupturas e permanências. Porto Alegre: UFRGS. 2009.

OLIVEIRA, Jefferson M. Gestão do conhecimento em instituições federais de ensino superior: o estudo de caso da universidade federal de Santa Maria. Porto Alegre: UFRGS. 2012.

PEREIRA, Elisabete M.de A. A universidade da modernidade nos tempos atuais. São Paulo: Scielo. 2009.

PERONI, Vera M. V; Redefinições no papel do Estado: Parcerias público-privadas e a democratização da educação. São Paulo: Scielo. 2012.

RIGO, Sandro J.; CAZELLA Sílvio C.; WAGNER Cambruzzi. Minerando Dados Educacionais com foco na evasão escolar: oportunidades, desafios e necessidades. Porto Alegre: UFRGS. 2014.

RODRIGUES, Cleide A. F; SCHMIDT, Leide M; MARINHO, Hermínia, B. Tutoria em Educação a Distância. Paraná: UEPG. 2011.

SAVIANI, Dermeval. A expansão do ensino superior no Brasil: mudanças e continuidades. Porto Alegre: UFRGS. 2010. 
SCHIAVON, Jaqueline E. Mídia: o papel das novas tecnologias na sociedade do conhecimento. Biblioteca Online de Ciências da Comunicação. 2008.

SILVA, Jorge P.; OURIQUE, Maiane L. H. A expansão da educação superior no Brasil: um estudo do caso Cesnors. Bagé: UNIPAMPA. 2012.

SANTOS, Átila P.; DOS SANTOS, Sandra I. F.; RISSOLI, Vandon R. V. A predição da evasão de estudantes de graduação como recurso de apoio fornecido por um assistente inteligente. Brasília: ABENGE. 2013.

SANTOS, Antônio A. A importância do conhecimento. Disponível em: $<$ http://www.administradores.com.br/artigos/tecnologia/a-importancia-do conhecimento/49020/>. Acesso em: 15 agosto 2015.

SOUSA, Boaventura S. A Universidade no século XXI: Para uma reforma democrática e emancipatória da Universidade. 3. Ed. São Paulo: Cortez, 2010.

VALENTIM, Marta L. P. Gestão da informação e do conhecimento e a importância da estrutura organizacional. São Paulo: UNESP. 2005.

VALLADARES. Licia. Os dez mandamentos da observação participante. São Paulo: Scielo. 2005.

VIEIRA, Eleonora M. F.; HERMENEGILDO, Jorge; MORAES, Marialice; ROSSATO, Jaqueline. Institucionalização da EaD nas Universidades Públicas: unicidade e gestão. Petrolina: UNIVASF. 2012. 